\title{
Concern over tattoo-related infections
}

Published online: 24 August 2012

(C) Springer Healthcare 2012

medwireNews: More care should be taken to prevent infections associated with tattooing, suggest researchers who describe a series of tattoo-related Mycobacterium chelonae infections in the USA.

Byron Kennedy (Monroe County Department of Public Health, Rochester, New York) and colleagues carried out an investigation after a dermatologist reported a case of tattoo-related M. chelonae infection in January 2012.

Writing in The New England Journal of Medicine, they found that 19 people in total (13 men; six women) in the Rochester area of New York had developed a persistent, raised red skin rash within 3 weeks of receiving a tattoo from a specific artist. The artist in question had used premixed gray ink for at least part of all the tattoos.

Skin biopsy samples taken from 17 of the 19 affected individuals confirmed infection with M. chelonae in 14 individuals using DNA sequencing. Of the other five people, four had probable and one had suspected M. chelonae infection. Eighteen of the 19 affected individuals were treated with antibiotics and recovered over time.

The investigators traced the bacterium to the gray ink used by the artist and the ink was subsequently recalled by the manufacturer.

"Even if a person receives a tattoo at a tattoo parlor that maintains the highest standards of hygienic practice, there remains a risk of infection from the use of contaminated ink," say Pamela LeBlanc and co-authors (Food and Drug Administration, Maryland, USA) in an accompanying perspective.

"People who get tattoos must be made aware of this risk and should seek medical attention if lesions consisting of red papules or a diffuse macular rash develop at the tattoo site," they add.

"Consumers should patronize artists who use sanitary tattooing practices and who can confirm that their inks have undergone a process that eliminates harmful microbial contaminants."

By Helen Albert, Senior medwireNews Reporter

\section{Reference}

N Engl J Med 2012; Advance online publication 